\title{
BMJ Open Outpatient healthcare use before and during a long-term sickness absence spell: a register-based follow-up study comparing healthcare use by the length of sickness absence and transition to disability pension in Finland
}

Riku Perhoniemi (D) , Jenni Blomgren (D)

To cite: Perhoniemi R, Blomgren J. Outpatient healthcare use before and during a long-term sickness absence spell: a register-based follow-up study comparing healthcare use by the length of sickness absence and transition to disability pension in Finland. BMJ Open 2022;12:e053948. doi:10.1136/ bmjopen-2021-053948

- Prepublication history for this paper is available online. To view these files, please visit the journal online (http://dx.doi org/10.1136/bmjopen-2021 053948).

Received 31 May 2021 Accepted 04 February 2022

\section{D) Check for updates}

(c) Author(s) (or their employer(s)) 2022. Re-use permitted under CC BY-NC. No commercial re-use. See rights and permissions. Published by BMJ.

The Social Insurance Institution of Finland (Kela), Research Unit, Helsinki, Finland

Correspondence to Riku Perhoniemi; riku.perhoniemi@kela.fi

\section{ABSTRACT}

Objectives The objective of the study was to examine outpatient healthcare use before and during a long-term sickness absence (LTSA), and to compare the development of healthcare use between groups defined through LTSA lengths and disability pension (DP) transition.

Design Register-based longitudinal study with five 6-month periods before and after the start of the LTSA spell in early 2016.

LTSA groups $1(\mathrm{~N}=210)$ and $2(\mathrm{~N}=187)$ went on to reach the statutory maximum LTSA length, with group 1 transitioning to DP. Group $3(\mathrm{~N}=3082)$ had a shorter LTSA spell. Control group 4 ( $\mathrm{N}=92$ 921) had no LTSA.

Setting and participants Non-retired individuals aged 20-59, with no LTSA during 2015 ( $\mathrm{N}=96$ 400) were included from the total population of the city of Oulu, Finland. Register data were linked on LTSA spells and outpatient healthcare use 2013-2018, DP status in 2018, and various covariates.

Main outcome measures Negative binomial regression models were used to examine the covariate-adjusted number of healthcare visits, and to examine the association of the LTSA groups with healthcare use before and after the start of LTSA (incidence rate ratios and predicted means)

Results Individuals eventually reaching the maximum LTSA length (groups 1 and 2) had a higher level of healthcare use before the LTSA and especially after the start of LTSA than others. Individuals transferring to DP after the maximum LTSA (group 1) used healthcare the most after the start of LTSA.

Conclusions The risk for at least 1 year's disability may be identified by frequent outpatient healthcare use years before LTSA. However, future disability retirees could not be identified through their pre-LTSA healthcare use. Instead, their high use of healthcare after the start of the LTSA was consistent with their increasing health problems leading to retirement.

\section{INTRODUCTION}

Both disability benefit spells and publicly reimbursed healthcare use cause enormous public expenses. ${ }^{12}$ As markers of ill health
Strengths and limitations of this study

- The data on outpatient healthcare use are based on comprehensive registers covering all schemes relevant to the Finnish working-age population and a 5 -year follow-up setting.

- The use of register data to define the number of visits, and on long-term sickness absence (LTSA) spells, disability pensioning, and covariates removes inaccuracy related to self-reporting.

- The study relies on total working-age population of the fifth largest city of Finland, Oulu.

- The study population is restricted to individuals with no LTSA in 2015, warranting caution in generalising the results to the whole working-age population.

- The study lacks better information on health status, work environment of employed persons, and diagnosis behind the LTSA, all known to associate with healthcare use.

and occupational disability, they both have mainly been treated in research literature as risk outcomes ${ }^{3-12}$ or as predictors of disability pensioning (DP). ${ }^{13-16}$ The association between long-term sickness absence (LTSA) and healthcare use is also evident. More frequent healthcare use is associated with more frequent and longer sickness absence spells later on. ${ }^{77-19}$ Vice versa, time spent on sick leave or DP associates with a higher frequency of healthcare use. ${ }^{9} 122021$

However, more information is needed about the temporal association between LTSA and healthcare use. We do not yet understand how healthcare use develops before and during a LTSA spell. Nor do we understand how the level of use varies according to the length and outcome of the LTSA spell. Following the level of healthcare 
use before occupational disability can reveal different profiles for groups with differing lengths and outcomes of sickness absence. This kind of knowledge may help identify groups in risk of long or permanent disability. On the other hand, understanding how healthcare use is related to different lengths of sickness absence or a transition to DP may help evaluate the functioning of the disability benefit or healthcare systems. If treatment and other supportive measures during LTSA are successful in shortening the disability spell or preventing DP, do shorter LTSA spells mean decreased healthcare use later as well? Correspondingly, do those who end up on DP have a distinctive healthcare use trajectory?

Only a few previous studies have focused on changes in healthcare use in relation to disability benefits. The level of healthcare use has been followed using register or survey data through the DP transition. The use of healthcare has been shown to decrease but remain high after the transition. ${ }^{22-24}$ In some studies, the level of healthcare use has also been followed before and after interventions as a measure of health and regained work ability, with sickness absence duration as a covariate. ${ }^{25-27}$ However, register-based follow-up studies on how the use of health services develops during sickness absence are still lacking.

In addition, when examining how the level of healthcare use develops before and during LTSA, it is necessary to account not only for the duration of the LTSA spells and a possible post-LTSA DP, but also for the effects of demographic, socioeconomic and disease-related covariates. ${ }^{3-11}$ The aim of this study was to examine whether the use of healthcare differed between different LTSA groups: individuals transferring to disability retirement after a maximum-length LTSA, individuals not transferring to disability retirement after a maximum-length LTSA, individuals with shorter LTSA spells, and individuals with no incident LTSA during the same time period.

\section{METHODS}

\section{Study population}

Register-based data for the years 2013-2018 were collected from several registers for the total population of the city of Oulu, situated in Northern Finland. ${ }^{28}$ Oulu is the fifth largest city of Finland, with a population of 207327 inhabitants in 2020. On various demographic, socioeconomic or healthcare-related indicators, Oulu does not differ in any systematic way from Finland as a whole. ${ }^{28}$ Individuals who were residents of Oulu, 20-59 years old, and not retired at the end of year 2015, and had no LTSAs during 2015, were included in this study $(\mathrm{N}=96400)$. Those receiving a pension at baseline were excluded, as pensioners are not entitled to sickness allowance. The lower and upper age limits were set so that the subjects would be of adult age and would not reach the lowest limit of old-age pension in Finland (63 years) during the follow-up years.

\section{Grouping based on LTSA and DP}

The study population was divided into groups according to having or not having incident LTSA spells during the first half of 2016, also using information on the length of sickness absence and whether or not they ended up on DP after the LTSA. LTSA was measured as the amount of compensated sickness allowance days. The Social Insurance Institution of Finland (Kela) can pay sickness allowance to non-retired persons aged 16-67 as compensation for loss of income due to inability to work because of sickness or impairment. The allowance can be paid when the sickness absence exceeds 10 working days, which are covered by the employer. Thus, sickness allowance captures only rather long sickness spells. A physician's sickness certificate is a prerequisite for the allowance. Based on a certain diagnosis, the allowance can generally be granted for 1 year at most during 2 years' time. After this statutory maximum period, a DP may be considered.

Register data on sickness allowance spells were derived from Kela, including the start dates of the illness and the end dates of compensated LTSA spells. Information on DP status at the end of 2018 was derived from the registers of Kela and the Finnish Center for Pensions.

The number of compensated LTSA days for the years 2016, 2017 and 2018 and data on DP from the end of 2018 were used to categorise subjects into four groups: Group 1 ( $\mathrm{N}=210)$ went on to reach the maximum length of compensated LTSA starting in the first half of 2016 (1 January-30 June), and transitioned to DP by the end of 2018. Group $2(\mathrm{~N}=187)$ eventually reached the maximum length of compensated LTSA starting in the first half of 2016, but did not transition to DP. Group 3 (N=3082) started a LTSA in the first half of 2016, but did not reach the maximum length of the LTSA period. Finally, a control group 4 ( $\mathrm{N}=92$ 921) had no LTSA spells in the first half of 2016. As this group did not have start dates for illness or LTSA spell, the start date of the follow-up was fixed to 1 April, the midpoint of the first half of 2016.

\section{Data on outpatient healthcare and the follow-up setting}

Data on the use of outpatient healthcare were collected for the years 2013-2018 covering all schemes (public, occupational, private) of the Finnish service system. Data on public healthcare use were obtained from the municipality of Oulu and from the Care Register for Health Care. ${ }^{29}$ Visits to municipal health centres and outpatient visits to hospital-based specialised care were equally included in public care. Data on occupational health service (OHS) attendance were gathered from the four largest OHS providers in Oulu (Terveystalo, Mehiläinen, Attendo and Työterveys Virta), estimated to cover around $92 \%$ of employees entitled to OHS. ${ }^{30}$ Data on the use of private outpatient care were retrieved from the reimbursement registers of Kela.

Public outpatient primary healthcare services, provided by municipal health centres, offer universal coverage for all residents. OHSs are the main provider of primary care services for the working population. All employees 
are entitled to at least employer-provided preventive care in OHS, but employers frequently also provide primary care through OHS. ${ }^{31}$ The use of private healthcare is state supported via partial reimbursement. The reimbursement varies by service, but it was $14 \%$ of the fee for a general practitioner visit in $2020 .^{32}$ Because of strong and affordable public and OHS schemes, role of the private scheme is still rather small in Finland. Outpatient specialised care is offered both by the public and private schemes, and to a small extent also by OHS.

Active visits to healthcare professionals, either faceto-face contacts, phone calls or virtual contacts, were included. Dental healthcare, public student healthcare and laboratory visits were excluded to harmonise the data between the schemes. As separate visits during the same day were inconsistently recorded in the registers of different register holders, the number of visits was approximated by separate attendance days with each healthcare provider. Finally, the total number of visits for each follow-up period (see below) was calculated for each subject.

The average number of outpatient healthcare visits was followed in five 6-month periods before and five 6-month periods after the start of the first sickness absence spell. The visit to obtain a sickness certificate from a physician (first day of illness), needed for the sickness allowance, was included in the first follow-up period.

\section{Covariates}

Since demographic and socioeconomic factors, along with morbidity, are associated with both the frequency and length of sickness absence ${ }^{3-5}$ and the level of healthcare use, ${ }^{79-12} 21$ they need to be adjusted for when examining the association between LTSA and healthcare use.

Sex, age, marital status, socioeconomic status and entitlement to reimbursements for medicine expenses at the end of 2015 were retrieved from registers of Kela. Unemployment benefit and employment spells were retrieved from registers of Kela and Finnish Centre for pensions.

The sample was classified into four age groups in 10-year age bands (see table 1). Marital status was classified as married, unmarried, and divorced, separated or widowed. Socioeconomic status was measured in terms of occupational class and educational level. Occupational class followed the classification used by Statistics Finland $^{33}$ and distinguished between upper and lower non-manual employees, manual workers, entrepreneurs and others. The group of 'others' included the long-term unemployed and other persons outside employment. Educational level was categorised into upper tertiary, lower tertiary, secondary and basic level education. Labour market status at the start of the LTSA was defined as either employed, unemployed or other. Entitlement to reimbursements for medicine expenses was used as a proxy measure for chronic disease. ${ }^{34}$ These entitlements are part of the National Health Insurance system and guarantee the recipients' access to medicines needed for the treatment of certain long-term diseases at a lower cost. A person can have one or multiple reimbursement entitlements. Here, a division between no diseases (no entitlements), one disease, and multiple chronic diseases was used.

\section{Statistical methods}

The average, unadjusted number of outpatient healthcare visits for the five 6-month periods before and the five 6-month periods after the start of the sickness absence spell were first calculated. Covariate-adjusted estimates for the number of outpatient healthcare visits for each period were then calculated using negative binomial regression models. This method is suitable for count data with a right-skewed distribution. ${ }^{35}$ Finally, the association of LTSA groups and covariates with the average number of healthcare visits before and after the start of the LTSA spell were analysed separately with two negative binomial regression models. For these two models, incidence rate ratios (IRRs) and predicted means for outpatient healthcare visits with their $95 \%$ CIs are presented. The analyses were conducted using Stata statistical software package V.14.1.

\section{Patient and public involvement}

No patient involved.

\section{RESULTS}

Table 1 shows the distributions of the covariates by LTSA group. The four groups were very different in size, as only a few of those on LTSA reached the maximum length of the allowance, and most individuals in the study population did not have any LTSA in the first half of 2016.

There were significant differences between the four groups. Compared with others, persons in group one were on average older, had more often only attained a basic level education, were more often outside employment (occupational class of others), and had more chronic diseases. Persons in group two had a similar socioeconomic profile as group one but were younger, had fewer chronic diseases and were more often unmarried. Persons in groups 1 and 2 were more often unemployed at the onset of disability than others. Group three had a relatively similar age and chronic disease profile as group 2, but included a clearly larger-than-average share of women and non-manual employees. Group three was also most often employed at the onset of disability. Group 4 , that is, those with no LTSA, comprised the majority of the study population. This group was younger and had fewer chronic diseases than other groups.

Figure 1 presents unadjusted averages for outpatient healthcare visits in each 6 month period before and after the start of sickness absence. Thirty to 7 months before the LTSA spell, the level of healthcare use was stable in each group, with groups 1 and 2 having more visits than others. One year before the first LTSA spell, healthcare use began to increase for all those who would later start 
Table 1 The covariates in the study population and by long-term sickness absence (LTSA) group

Group 1: maximum Group 2:

LTSA spell, transferred maximum LTSA Group 3: less than Group 4: no

\begin{tabular}{|c|c|c|c|c|}
\hline All & to DP & spell, no DP & maximum LTSA & LTSA \\
\hline $\mathrm{N}=96400$ & $\mathrm{~N}=\mathbf{2 1 0}$ & $\mathrm{N}=187$ & $\mathrm{~N}=3082$ & $\mathrm{~N}=92921$ \\
\hline$\%$ & $\%$ & $\%$ & $\%$ & $\%$ \\
\hline
\end{tabular}

\begin{tabular}{|lccccc|}
\hline Sex & & & & & \\
\hline Male & 52.4 & 49.5 & 49.7 & 38.8 & 52.8 \\
\hline Female & 47.6 & 50.5 & 50.3 & 61.2 & 47.2 \\
\hline Age group & & & & & 32.6 \\
\hline $20-29$ & 32.1 & 16.2 & 23.0 & 20.3 & 27.0 \\
\hline $30-39$ & 26.9 & 14.3 & 24.1 & 24.4 & 21.0 \\
\hline $40-49$ & 21.1 & 19.5 & 23.5 & 24.1 & 19.5 \\
\hline $50-59$ & 19.9 & 50.0 & 29.4 & 31.2 & 41.2 \\
\hline Marital status & & & & & 49.4 \\
\hline Married & 41.3 & 45.7 & 36.4 & 45.6 & 9.4 \\
\hline Unmarried & 49.0 & 33.8 & 46.0 & 38.9 & 15.6 \\
\hline Divorced/separated & 9.7 & 20.5 & 17.7 & & \\
\hline
\end{tabular}

/widowed

Educational level

\begin{tabular}{|c|c|c|c|c|c|}
\hline Upper tertiary & 17.0 & 10.0 & 5.9 & 14.6 & 17.1 \\
\hline Lower tertiary & 25.4 & 22.4 & 12.8 & 28.1 & 25.4 \\
\hline Secondary & 47.2 & 51.4 & 65.2 & 48.2 & 47.2 \\
\hline Basic & 10.4 & 16.2 & 16.0 & 9.1 & 10.4 \\
\hline \multicolumn{6}{|l|}{ Occupational class } \\
\hline $\begin{array}{l}\text { Upper non-manual } \\
\text { employee }\end{array}$ & 21.2 & 8.6 & 9.1 & 18.6 & 21.3 \\
\hline $\begin{array}{l}\text { Lower non-manual } \\
\text { employee }\end{array}$ & 25.9 & 17.1 & 17.1 & 39.5 & 25.5 \\
\hline Manual worker & 17.0 & 18.1 & 19.8 & 21.0 & 16.8 \\
\hline Entrepreneur & 5.3 & 5.2 & 7.5 & 4.4 & 5.3 \\
\hline Other & 30.7 & 51.0 & 46.5 & 16.5 & 31.1 \\
\hline \multicolumn{6}{|c|}{ Labour market status at the start of LTSA } \\
\hline Employed & 68.2 & 46.2 & 46.0 & 84.7 & 67.7 \\
\hline Unemployed & 16.4 & 39.5 & 33.7 & 8.9 & 16.5 \\
\hline Other & 15.5 & 14.3 & 20.3 & 6.4 & 15.8 \\
\hline \multicolumn{6}{|l|}{ Chronic diseases } \\
\hline No & 85.0 & 58.1 & 74.3 & 76.4 & 85.4 \\
\hline One disease & 12.2 & 28.6 & 21.9 & 18.3 & 12.0 \\
\hline Multiple diseases & 2.8 & 13.3 & 3.7 & 5.3 & 2.6 \\
\hline All & 100.0 & 100.0 & 100.0 & 100.0 & 100.0 \\
\hline
\end{tabular}

an LTSA spell (groups 1, 2 and 3). Six months before the spell, the increase steepened.

During the first 6 months of LTSA, healthcare use peaked for all three groups. After that, the use decreased in groups 2 and 3. However, for group 1, use of healthcare increased until months 7 to 12 of the LTSA, before starting to gradually decrease. The group differences were mostly statistically significant for all ten 6 months periods (see confidence intervals). However, the differences between groups 1 and 2 were only statistically significant for months 13 to 30. For group 4, the level of healthcare use remained stable and lower for the whole follow-up.

Adjusting for covariates narrowed the differences between the levels of healthcare use between groups 1 and 2 marginally (predicted means in figure 2). Most notably, the visually detectable but very slight difference 
25

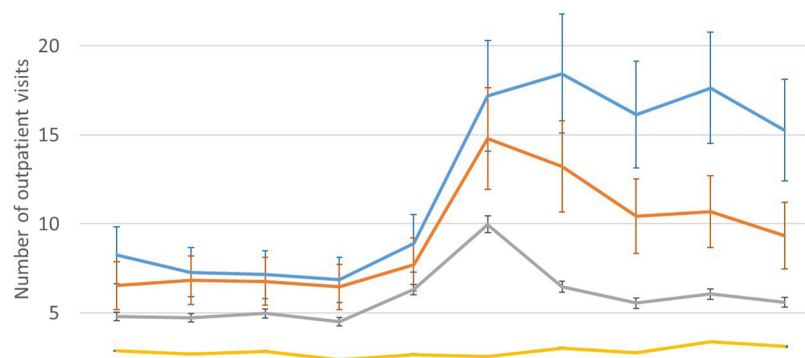

0

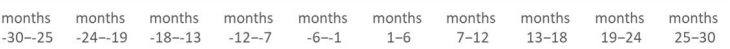

Months before and after the start of the LTSA spell

-Group 1: Maximum LTSA spell and transferred to DP

—Group 2: Maximum SA spell, no DP

-Group 3: Less than maximum LTSA

-Group 4: No LTSA

Figure 1 Outpatient healthcare use in the four LTSA groups.

in average use before the start of the LTSA between groups 1 and 2 disappeared. Instead, adjusting for covariates marginally increased how group three differed from groups 1 and 2 in its average healthcare use 6 to 1 months before the start of the LTSA.

Finally, the association of LTSA groups and covariates with the average outpatient healthcare visits were examined before and after the start of the LTSA spell. The results of the negative binomial regression models are presented in table 2 . The LTSA group variable and covariates were entered into the models simultaneously. Group one served as the reference group in the analyses.

The first four columns present results for the time before the LTSA spell. As was seen in figure 2, the level of healthcare use was highest in groups 1 (predicted mean 5.63) and 2 (predicted mean 5.66), lower in group 3 (IRR

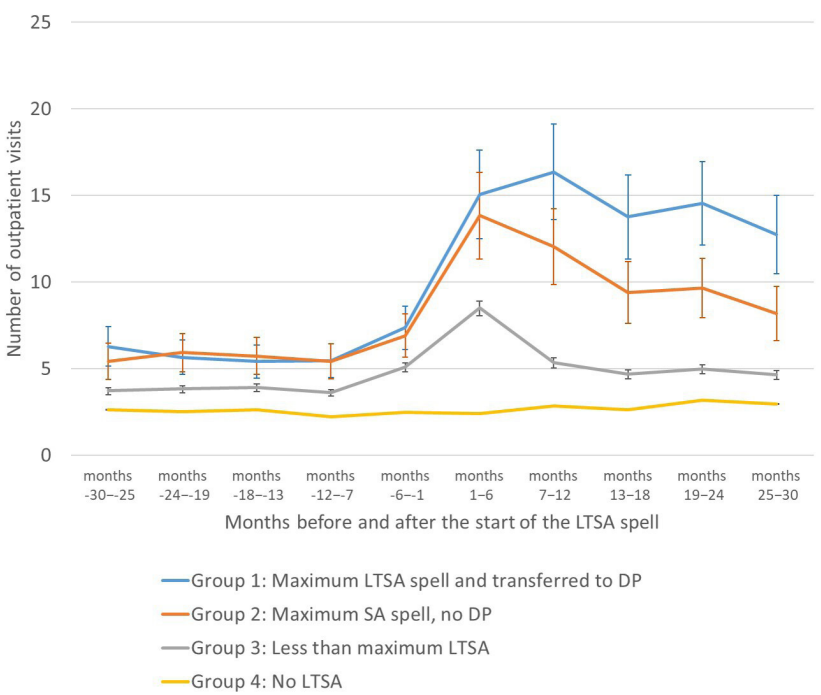

Figure 2 Covariate-adjusted outpatient healthcare use in the four LTSA groups (predicted means for visits).
0.71 compared with group 1 , predicted mean 3.97 ), and lowest in group 4 (IRR 0.44 , predicted mean 2.47 ), when adjusted for covariates. The level of healthcare use did not differ between groups 1 and 2 .

The last four columns in table 2 present results for the time after the start of the LTSA spell, respectively. Adjusting for covariates, the level of healthcare use was highest in group 1 (13.92), second highest in group 2 (IRR 0.76 compared with group 1, predicted mean 10.53), second lowest in group 3 (IRR 0.40 , predicted mean 5.54), and lowest in group 4 (IRR 0.20 , predicted mean 2.78). The differences between LTSA groups after the start of the LTSA spell were larger than before LTSA.

The associations between covariates and outpatient healthcare use were largely similar before and after the start of LTSA. Females used outpatient healthcare more than males, persons between 50 and 59 years more than younger age groups, and 20-29year olds less than other age groups. Those divorced, separated or widowed used healthcare more than other groups. Those with only basic education or with secondary education had more visits than those with tertiary education. Also, lower nonmanual employees and manual workers had more visits than other occupational classes. Entrepreneurs used outpatient healthcare less than other occupational class groups. Those unemployed at the start of LTSA had slightly more visits than others before the LTSA spell. Finally, an increasing number of chronic diseases was strongly associated with increased level of healthcare use.

\section{DISCUSSION}

There is insufficient information about the temporal association between sickness absence and healthcare use. Understanding this association better can help identify groups in risk of long or permanent disability, and also help evaluate how well the interplay of disability benefit and healthcare systems works. Our study shows that the development of outpatient healthcare use before and during an incident LTSA varies according to the length and outcome of the LTSA spell. The trajectories of healthcare use were compared between four groups: those who eventually transferred to DP after reaching the maximum length of compensated LTSA (group 1), those who did not transfer to DP after reaching the maximum LTSA spell (group 2), those who had a LTSA spell shorter than the maximum length (group 3), and those with no LTSA (control group 4).

\section{Outpatient healthcare use before LTSA}

Individuals who went on to reach the maximum length of compensated LTSA (groups 1 and 2) used healthcare more than others in the study population before the LTSA, controlling for demographic and socioeconomic covariates and chronic diseases. Notably, their level of use was significantly and steadily higher already years before their sickness absence started, compared with those who had a shorter (less than the maximum length) LTSA 
Table 2 The long-term sickness absence (LTSA) groups and covariates associated with the average level of outpatient healthcare use (a) before LTSA, and (b) after LTSA in a negative binomial regression analysis model

\begin{tabular}{|c|c|c|c|c|c|c|c|c|}
\hline & \multicolumn{4}{|c|}{ Before LTSA } & \multicolumn{4}{|c|}{ After the start of LTSA } \\
\hline & IRR & $95 \% \mathrm{Cl}$ & $\begin{array}{l}\text { Predicted } \\
\text { means }\end{array}$ & $95 \% \mathrm{Cl}$ & IRR & $95 \% \mathrm{Cl}$ & $\begin{array}{l}\text { Predicted } \\
\text { means }\end{array}$ & $95 \% \mathrm{Cl}$ \\
\hline $\begin{array}{l}\text { Group 1: Maximum LTSA } \\
\text { spell and transferred to DP }\end{array}$ & 1.00 & & 5.63 & 4.99 to 6.27 & 1.00 & & 13.92 & 12.37 to 15.46 \\
\hline $\begin{array}{l}\text { Group 2: Maximum LTSA } \\
\text { spell, no DP }\end{array}$ & 1.00 & 0.85 to 1.19 & 5.66 & 4.97 to 6.34 & 0.76 & 0.64 to 0.89 & 10.53 & 9.27 to 11.79 \\
\hline Group 4: no LTSA & 0.44 & 0.39 to 0.49 & 2.47 & 2.45 to 2.49 & 0.20 & 0.18 to 0.22 & 2.78 & 2.77 to 2.80 \\
\hline \multicolumn{9}{|l|}{ Sex } \\
\hline Male & 1.00 & & 1.98 & 1.96 to 2.00 & 1.00 & & 2.31 & 2.29 to 2.33 \\
\hline $30-39$ & 1.23 & 1.21 to 1.26 & 2.68 & 2.65 to 2.72 & 1.13 & 1.11 to 1.15 & 2.92 & 2.89 to 2.96 \\
\hline $40-49$ & 1.22 & 1.19 to 1.24 & 2.65 & 2.62 to 2.69 & 1.15 & 1.12 to 1.17 & 2.96 & 2.91 to 3.00 \\
\hline $50-59$ & 1.27 & 1.25 to 1.30 & 2.77 & 2.73 to 2.81 & 1.23 & 1.21 to 1.26 & 3.19 & 3.14 to 3.23 \\
\hline \multicolumn{9}{|l|}{ Marital status } \\
\hline Married & 1.00 & & 2.54 & 2.52 to 2.57 & 1.00 & & 2.85 & 2.83 to 2.88 \\
\hline Unmarried & 0.96 & 0.94 to 0.97 & 2.43 & 2.41 to 2.46 & 0.98 & 0.97 to 1.00 & 2.80 & 2.77 to 2.83 \\
\hline $\begin{array}{l}\text { Divorced/separated/ } \\
\text { widowed }\end{array}$ & 1.13 & 1.11 to 1.15 & 2.87 & 2.82 to 2.93 & 1.13 & 1.11 to 1.16 & 3.23 & 3.17 to 3.30 \\
\hline \multicolumn{9}{|l|}{ Educational level } \\
\hline Upper tertiary & 1.00 & & 2.42 & 2.37 to 2.46 & 1.00 & & 2.76 & 2.71 to 2.81 \\
\hline $\begin{array}{l}\text { Lower non-manual } \\
\text { employee }\end{array}$ & 1.11 & 1.09 to 1.13 & 2.74 & 2.70 to 2.78 & 1.16 & 1.13 to 1.18 & 3.12 & 3.08 to 3.16 \\
\hline Manual worker & 1.06 & 1.04 to 1.09 & 2.63 & 2.58 to 2.67 & 1.09 & 1.06 to 1.11 & 2.93 & 2.88 to 2.98 \\
\hline Entrepreneur & 0.69 & 0.67 to 0.71 & 1.71 & 1.66 to 1.76 & 0.70 & 0.68 to 0.72 & 1.89 & 1.83 to 1.94 \\
\hline Other & 1.01 & 0.98 to 1.03 & 2.49 & 2.45 to 2.52 & 1.09 & 1.07 to 1.12 & 2.95 & 2.90 to 2.99 \\
\hline \multicolumn{9}{|c|}{ Labour market status at the start of LTSA } \\
\hline Employed & 1.00 & & 2.55 & 2.53 to 2.58 & 1.00 & & 2.96 & 2.93 to 2.98 \\
\hline Unemployed & 1.07 & 1.05 to 1.10 & 2.75 & 2.70 to 2.80 & 1.02 & 1.00 to 1.05 & 3.02 & 2.97 to 3.08 \\
\hline Other & 0.84 & 0.82 to 0.86 & 2.16 & 2.12 to 2.20 & 0.80 & 0.78 to 0.82 & 2.35 & 2.31 to 2.40 \\
\hline \multicolumn{9}{|l|}{ Chronic diseases } \\
\hline No & 1.00 & & 2.28 & 2.27 to 2.29 & 1.00 & & 2.64 & 2.62 to 2.66 \\
\hline One disease & 1.85 & 1.82 to 1.88 & 4.21 & 4.14 to 4.28 & 1.63 & 1.60 to 1.65 & 4.29 & 4.22 to 4.36 \\
\hline Multiple diseases & 2.61 & 2.52 to 2.69 & 5.93 & 5.74 to 6.12 & 2.16 & 2.08 to 2.23 & 5.70 & 5.51 to 5.89 \\
\hline
\end{tabular}

All predictors adjusted simultaneously in the models (all-adjusted models).

spell (group 3). Thus, frequent outpatient healthcare use seems to anticipate very long occupational disability already years before the disability actualises. Possibly, the condition causing eventual disability can be chronic long before the LTSA spell, accounting for the early frequent healthcare use. Multimorbidity may also explain the high 
early level of healthcare use in groups 1 and 2, as having multiple health-related conditions predicts long LTSA spells, DP and more frequent healthcare use. ${ }^{36-41}$ In our analysis, a proxy measure for chronic diseases reflecting multiple diseases was controlled for among other covariates, and this changed the differences between LTSA groups very little. It is noteworthy that the level of healthcare use years before LTSA spell did not distinguish between groups 1 and 2, that is, those who would eventually transfer to DP and those who would not. In other words, although based on previous literature frequent outpatient healthcare use is a risk factor for DP over the following years, ${ }^{71642}$ our results suggest that the risk of DP cannot be distinguished from the more general risk of long-term sickness associated with early outpatient healthcare use.

Individuals who had a LTSA spell of less than 1 year (group 3) also had consistently more outpatient healthcare visits from 2.5 years before the LTSA spell to the start of the spell compared with individuals with no LTSA. While there is no uniform distinction between a short-term and LTSA, this consistent and early difference shows that individuals with at least some long-term compensated sickness absence often have more severe or chronic health conditions even before the LTSA spell, compared with individuals that either do not have a need for sickness absence or their sickness absence is of a short duration (self-certified or employer covered). LTSA is most often caused by mental disorders or musculoskeletal diseases, ${ }^{43-45}$ while short absences are usually caused by transient medical conditions. In addition, group 3 included more employed individuals than other LTSA groups. Many employed individuals with a LTSA have physically or mentally demanding working conditions, ${ }^{46} 47$ causing OHS healthcare visits already before the disability period. Lastly, as there were relatively more persons outside employment in group 4 than 3 , and they may hesitate to use healthcare for financial reasons, ${ }^{48} 49$ this may add to the very low level of healthcare use in this group. While occupational class and labour market status at the start of LTSA were controlled for, the effects of working conditions and underuse of healthcare may still explain some amount of the group differences in healthcare use.

\section{Outpatient healthcare use after the start of LTSA}

In terms of outpatient healthcare use, the LTSA groups differed from each other more after the start of the LTSA spell than before it. Those who eventually transferred to DP (group 1) had the highest level of healthcare use after the start of the LTSA. The level was also higher among group 1 than among non-retiring individuals who reached the maximum length of compensated LTSA (group 2), although the difference was statistically significant only 1 , 5 years after the start of LTSA. If outpatient healthcare use is used as a measure of ill health, our results may indicate that healthcare and pension systems successfully identify those with disabling health problems. Earlier studies on health symptom trajectories ${ }^{50}$ and psychotropic drug consumption ${ }^{5152}$ have shown somewhat similar results-a steep rise in the disability indicators before the pension grant, and a steady long decline after the pension grant. In this study, the decrease in use for group 1 started after the first follow-up year. This is the earliest possible time point for reaching the maximum LTSA length and transferring to a DP. Perhoniemi et $a \tilde{l}^{1}$ also found a higher psychotropic drug consumption level after the pension decision for DP retirees compared with the rejected DP applicants. On the other hand, a higher level of healthcare use in group 1 may reflect a better standard of care. It is possible that those transferring to DP benefited from a more rigorous initial attempt to improve their functional capacity. More healthcare visits may also mean more accurate documentation of occupational disability, increasing their chances to qualify for a pension. As these interpretations are not mutually exclusive, they can all play a role.

All individuals that eventually would reach the maximum length of compensated LTSA experienced a steep rise in healthcare use starting 6 months before the start of the LTSA spell, a peak in the first LTSA year, and a gradual, long decrease after that peak. The early peak is partly a consequence of the mandatory physician visits to receive sickness allowance. Usually, multiple visits and certificates are needed early on as the physician monitors the development of the health condition if it continues to cause occupational disability. For some of the disability retirees, possibly retiring already before the end of 2018, the gradually decreasing healthcare use can reflect a decreasing incentive to improve functional capacity once they have qualified for a pension. For those not transferring to a pension, the decrease may be explained by two processes: For those returning to work, the decrease after a high level of care use may reflect successful restoration of work ability by means of treatment or rehabilitation. In contrast, for those who after prior employment faced unemployment instead of DP or return to work, the decreasing level may in fact reflect lesser chances for care after losing their access to OHS. For group 2, we ran additional analyses on their labour market status in the end of the follow-up, and on their rejected DP applications. Circa half $(51 \%)$ of group 2 faced unemployment and one-third (35\%) were employed during the last 6-month period of the follow-up. In the total study population, the corresponding proportions were $20 \%$ and $86 \%$ respectively. $60 \%$ of group 2 also had a rejected DP application after the start of LTSA. These figures reflect a high risk of marginalisation among those in group 2 if DP is not granted but work ability is not regained either. ${ }^{53}$

In spite of the gradual decrease, groups 1 and 2 showed relatively frequent healthcare use up until the end of the maximum LTSA. In addition to the original medical causes responsible for the sickness absence and healthcare visits, the negative consequences of sickness absence per se also may contribute to healthcare visits during the LTSA. Long sickness absence has been associated with risks for inactivity, social isolation, sleep disturbance, 
lower self-rated health and decreased psychological well-being. ${ }^{54-56}$

For those who had a LTSA spell of less than a year (group 3), the attendance trajectory was very unsurprising, showing a mild peak around the start of LTSA, and a steep decline thereafter. Most often $(64 \%)$ even the LTSA spells are not more than 30 days long, ${ }^{57}$ thus not requiring several healthcare visits afterwards.

\section{Methodological considerations}

Our study population was defined using register data on the total working-age population of the city of Oulu, Finland, linked to register data on healthcare use, LTSA spells, DP and covariates. Unlike in many other studies, data on healthcare use were based on comprehensive registers covering all schemes relevant to the Finnish working-age population. Registers are deemed to be highly reliable and objective, with very little missing information, no self-report bias and no loss to follow-up. Furthermore, both the number of outpatient healthcare visits, approximated with attendance days, and the precise length of the sickness absence spells could be calculated reliably.

However, a limitation is the restriction of our study population to individuals with no LTSA or pensions in the previous year. This of course warrants caution in generalising the results to the whole working-age population in Finland. Furthermore, our data were drawn from one Finnish city. While the general social security and healthcare systems are similar all over the country, the results may not be generalisable to other social security systems. Our proxy measure for chronic disease, entitlements to reimbursements for medicine expenses, was not ideal. These reimbursements are most often used for diseases of the circulatory system, diabetes or asthma, whereas in disability benefits the emphasis is strongly on mental disorders and musculoskeletal diseases. ${ }^{58}$ Furthermore, we lacked more complete information on health status or the physical and psychosocial work environment that could explain some of the differences between the healthcare use trajectories in the four LTSA groups. Future studies should also control or stratify between different diagnostic groups, whether from healthcare use or sickness absence data. Our healthcare data did not include information on diagnosis, which can affect both the level of healthcare use ${ }^{8215960}$ and the length and consequence of sickness absence. ${ }^{43-4561-63}$ Further, group 2 was heterogeneous in their paths after the maximum LTSA period, shown by our additional analysis on labour market status and rejected DP applications. However, due to data size limitation, we could not treat those subjects as different subgroups in our analyses. Future studies with larger data sets could also provide more detailed analyses on healthcare use of rejected DP applicants.

\section{CONCLUSIONS}

Our results show that individuals who go on to reach the maximum 1 year's length of compensated LTSA use outpatient healthcare more than others not only after the start of their sickness absence spell, but also years before the spell started. Thus, individuals with a risk for very long disability may be identified based on frequent outpatient healthcare use years before the first sickness absence spell. However, our results imply that those who end up transferring to DP cannot be identified from others who reach the maximum LTSA spell on the basis of early healthcare use. Nevertheless, those who eventually end up on disability retirement have the highest level of healthcare use after the start of the LTSA, indicating that healthcare and pension systems successfully identify disabling health problems. It is crucial to understand the ways both disability benefits and use of healthcare cause public expenses, and to find a balance between efficient, equal care and lower costs.

Twitter Riku Perhoniemi @perhonir

Contributors Both authors contributed to the planning and conducting the study. $\mathrm{RP}$ wrote first and successive drafts of the manuscripts, and conducted the statistical analyses. JB contributed in writing and revising the manuscript, and advised on statistical modelling. Both authors interpreted the results and approved the final version/revision of the manuscript. RP: guarantor.

Funding This study was funded by the Social Insurance Institution of Finland (Kela).

Competing interests None declared.

Patient and public involvement Patients and/or the public were not involved in the design, or conduct, or reporting, or dissemination plans of this research.

Patient consent for publication Not applicable.

Ethics approval The study used secondary data from registers. Following the guidelines of the Finnish National Board on Research Integrity, an ethical review statement is not required for studies based solely on administrative register data. Good scientific practice and data protection procedures and regulations were followed. City of Oulu, Kela, Statistics Finland and Finnish Institute of Health and Welfare provided permissions for the use of the register data.

Provenance and peer review Not commissioned; externally peer reviewed.

Data availability statement No data are available. Data cannot be shared publicly because strict restrictions apply to the availability of confidential individual-level register data. These analyses were conducted with permissions from third-party data holders for the current study. Permissions to obtain register data from the City of Oulu, from the Social Insurance Institution of Finland (Kela) and from the occupational health care providers may be applied for scientific research purposes from the Finnish Health and Social Data Permit Authority Findata (https://www. findata.fi/en/). A license to obtain register data from Statistics Finland may be applied for separately (https://www.tilastokeskus.fi/meta/tietosuoja/kayttolupa_en. html).

Open access This is an open access article distributed in accordance with the Creative Commons Attribution Non Commercial (CC BY-NC 4.0) license, which permits others to distribute, remix, adapt, build upon this work non-commercially, and license their derivative works on different terms, provided the original work is properly cited, appropriate credit is given, any changes made indicated, and the use is non-commercial. See: http://creativecommons.org/licenses/by-nc/4.0/.

\section{ORCID iDs}

Riku Perhoniemi http://orcid.org/0000-0002-3199-3952 Jenni Blomgren http://orcid.org/0000-0001-5466-0205

\section{REFERENCES}

1 OECD. Sickness, disability and work: Breaking the barriers - a synthesis of findings across OECD countries. Paris: OECD, 2010.

2 OECD. Public spending on incapacity, 2020. Available: https://data. oecd.org/socialexp/public-spending-on-incapacity.htm\#indicatorchart [Accessed 3 Jul 2020]. 
3 Laaksonen M, Mastekaasa A, Martikainen P, et al. Gender differences in sickness absence--the contribution of occupation and workplace. Scand J Work Environ Health 2010;36:394-403.

4 Löve J, Hensing G, Holmgren K, et al. Explaining the social gradient in sickness absence: a study of a general working population in Sweden. BMC Public Health 2013;13:545-53.

5 Beemsterboer W, Stewart R, Groothoff J, et al. A literature review on sick leave determinants (1984-2004). Int J Occup Med Environ Health 2009:22:169-79.

6 Blomgren J, Jäppinen S. Incidence and length of sickness absence among hierarchical occupational classes and Non-Wage-Earners: a register study of 1.6 million Finns. Int $J$ Environ Res Public Health 2021;18:501.

7 Bergh $\mathrm{H}$, Baigi A, Månsson J, et al. Predictive factors for longterm sick leave and disability pension among frequent and normal attenders in primary health care over 5 years. Public Health 2007:121:25-33.

8 Foster A, Jordan K, Croft P. Is frequent attendance in primary care disease-specific? Fam Pract 2006:23:444-52.

9 Karlsson H, Lehtinen V, Joukamaa M. Frequent attenders of Finnish public primary health care: sociodemographic characteristics and physical morbidity. Fam Pract 1994:11:424-30.

10 Pymont C, Butterworth P. Longitudinal cohort study describing persistent frequent attenders in Australian primary healthcare. BMJ Open 2015;5:e008975

11 Sumanen $\mathrm{H}$, Harkko J, Piha K, et al. Association between socioeconomic position and occupational health service utilisation trajectories among young municipal employees in Finland. BMJ Open 2019:9:e028742.

12 Vedsted $\mathrm{P}$, Olesen $\mathrm{F}$. Social environment and frequent attendance in Danish general practice. Br J Gen Pract 2005;55:510-5.

13 Kivimäki M, Ferrie J, Hagberg J. Diagnosis-specific sick leave as a risk marker for disability pension in a Swedish population. $J$ Epidemiol Com Health 2007:61:915-20.

14 Alexanderson K, Kivimäki M, ym FJ. Diagnosis-specific sick leave as a long-term predictor of disability pension:. aA 13-year follow-up of the GAZEL cohort study. J Epidemiol Com Health 2012;2012:155-9.

15 Salonen L, Blomgren J, Laaksonen M, et al. Sickness absence as a predictor of disability retirement in different occupational classes: a register-based study of a working-age cohort in Finland in 20072014. BMJ Open 2018;8:e020491.

16 Mittendorfer-Rutz E, Härkänen T, Tiihonen J, et al. Association of socio-demographic factors, sick-leave and health care patterns with the risk of being granted a disability pension among psychiatric outpatients with depression. PLoS One 2014;9:e99869.

17 Ropponen A, Gémes K, Frumento P, et al. Predicting the duration of sickness absence spells due to back pain: a population-based study from Sweden.. Occup Environ Med 2020;77:115-21.

18 Reho TTM, Atkins SA, Talola N, et al. Occasional and persistent frequent attenders and sickness absences in occupational health primary care: a longitudinal study in Finland. BMJ Open 2019;9:e024980.

19 Harkko J, Sumanen H, Pietiläinen O, et al. Socioeconomic differences in occupational health service utilization and sickness absence due to mental disorders: a register-based retrospective cohort study. Int J Environ Res Public Health 2020;17:e2064.

20 Al-Windi A, Elmfeldt D, Svärdsudd K. The influence of sociodemographic characteristics on health care utilisation in a Swedish municipality. Ups J Med Sci 2004;109:33-42.

21 Jyväsjärvi S, Keinänen-Kiukaanniemi S, Väisänen E, et al. Frequent attenders in a Finnish health centre: morbidity and reasons for encounter. Scand J Prim Health Care 1998;16:141-8.

22 Højsted J, Alban A, Hagild K, et al. Utilisation of health care system by chronic pain patients who applied for disability pensions. Pain 1999;82:275-82.

23 Edén L, Ejlertsson G, Leden I. Health and health care utilization among early retirement pensioners with musculoskeletal disorders. Scand J Prim Health Care 1995;13:211-6.

24 Wallman T, Burel G, Kullman S, et al. Health care utilisation before and after retirement due to illness. A 13-year population-based follow-up study of prematurely retired men and referents from the general population. Scand J Prim Health Care 2004;22:95-100.

25 Görge M, Ziehm J, Farin E. Health-care use of patients with chronic back pain before and after rehabilitation. BMC Health Serv Res 2017;17:812-21

26 Momsen A-MH, Stapelfeldt CM, Nielsen CV, et al. Effects of a randomized controlled intervention trial on return to work and health care utilization after long-term sickness absence. BMC Public Health 2016;16:1149-60.
27 Stein KF, Miclescu A. Effectiveness of multidisciplinary rehabilitation treatment for patients with chronic pain in a primary health care unit. Scand J Pain 2013;4:190-7.

28 Blomgren J, Jäppinen S. Sosiaali- ja terveyspalveluiden ja etuuksien käyttö Oulussa 2013-2018. Tutkimushankkeen aineiston yleiskuvaus [Social and health care services and social security benefits in Oulu in 2013-2018. Basic description of data] (In Finnish, with English abstract). Kela Working papers 2020.

29 Gissler M, Haukka J. Finnish health and social welfare registers in epidemiological research. Norsk Epidemiologi 2004;14:113-20.

30 Hujanen T, Mikkola H. Työterveyshuollon kustannuskehitys [Cost development of occupational health services] (In Finnish, with English abstract). Suom Laakaril 2016;71:1537-40.

31 Räsänen K, Heikkinen J, Myllykangas M. Työterveyshuollon sairaanhoitopalvelujen käyttö vaihtelee tarjonnan mukaan [Supply and use of consultation services in occupational health units in the nine biggest cities in Finland] (Article in Finnish, with English summary). Suom Laakaril 2014;69:1325-30.

32 Kela. Kelan sairausvakuutustilasto. [Statistics on sickness insurance 2020] (Report in Finnish). Official Statistics of Finland, 2020. Available: https://helda.helsinki.fi/handle/10138/334684 [Accessed 1 Dec 2021].

33 Statistics Finland. Sosioekonominen asema 1989 [Classification of socioeconomic groups 1989]. Available: https://www.stat.fi/meta/ luokitukset/sosioekon_asema/001-1989/index.html [Accessed 10 Mar 2018].

34 Saastamoinen L, Aaltonen K, Maljanen T. Health registers as a source of data for research and policy making. Dosis 2012;28:199-205.

35 Cameron A, Trivedi P. Microeconometrics using Stata. Revised ed. Texas: Stata Press, 2010.

36 Ubalde-Lopez M, Delclos GL, Benavides FG, et al. The effect of multimorbidity on sickness absence by specific diagnoses. Occup Med 2017;67:93-100.

37 Salisbury C, Johnson L, Purdy S, et al. Epidemiology and impact of multimorbidity in primary care: a retrospective cohort study. Br J Gen Pract 2011:61:12-21.

38 Gill D, Sharpe M. Frequent consulters in general practice: a systematic review of studies of prevalence, associations and outcome. J Psychosom Res 1999;47:115-30.

39 Droomers M, Westert G. Do lower socioeconomic groups use more health services. because they suffer from more illnesses? Eur $J$ Public Health 2004;14:311-3.

40 Sundstrup E, Jakobsen MD, Mortensen OS, et al. Joint association of multimorbidity and work ability with risk of long-term sickness absence: a prospective cohort study with register follow-up. Scand J Work Environ Health 2017:43:146-54.

41 Ervasti J, Vahtera J, Pentti J, et al. The role of psychiatric, cardiometabolic, and musculoskeletal comorbidity in the recurrence of depression-related work disability. Depress Anxiety 2014;31:796-803.

42 Reho TTM, Atkins SA, Talola N, et al. Frequent attenders at risk of disability pension: a longitudinal study combining routine and register data. Scand J Public Health 2020;48:181-9.

43 Alexanderson K, Norlund A. Swedish Council on technology assessment in health care (SBU). Chapter 1. AIM, background, key concepts, regulations, and current statistics. Scand J Public Health Supp/ 2004;63:12-30.

44 Blomgren J, Perhoniemi R. Increase in sickness absence due to mental disorders in Finland: trends by gender, age and diagnostic group in 2005-2019. Scand J Public Health 2021:1403494821993705.

45 Hensing G, Andersson L, Brage S. Increase in sickness absence with psychiatric diagnosis in Norway: a general population-based epidemiologic study of age, gender and regional distribution. BMC Med 2006;4:19-27.

46 Vahtera J, Kivimäki M, Pentti J, et al. Effect of change in the psychosocial work environment on sickness absence: a seven year follow up of initially healthy employees. J Epidemiol Community Health 2000;54:484-93.

47 Lund T, Labriola M, Christensen KB, et al. Physical work environment risk factors for long term sickness absence: prospective findings among a cohort of 5357 employees in Denmark. BMJ 2006;332:449-52.

48 Hannikainen K. Ikääntyneiden sosiaali- ja terveyspalveluiden tarve ja käyttö eroavat tulotason mukaan [The use of social and health service differ by income in elderly population] (In Finnish), 2018. Available: https://www.julkari.fi/bitstream/handle/10024/136061/ URN_ISBN_978-952-343-067-9.pdf?sequence=1\&isAllowed=y.Study Brief $3 /$ 
49 Ahs $\mathrm{AMH}$, Westerling $\mathrm{R}$. Health care utilization among persons who are unemployed or outside the labour force. Health Policy 2006;78:178-19.

$50 \varnothing$ verland S, Glozier N, Henderson M, et al. Health status before, during and after disability pension Award: the Hordaland health study (husk). Occup Environ Med 2008;65:769-73.

51 Perhoniemi R, Tuulio-Henriksson A, Blomgren J, et al. Consumption of psychotropic drugs among disability pension applicants with mental disorders: comparing awarded and rejected applicants in Finland. Soc Psychiatry Psychiatr Epidemiol 2021;56:437-48.

52 Laaksonen M, Metsä-Simola N, Martikainen P, et al. Trajectories of mental health before and after old-age and disability retirement: a register-based study on purchases of psychotropic drugs. Scand J Work Environ Health 2012;38:409-17.

53 Perhoniemi R, Blomgren J, Laaksonen M. Sources of income following a rejected disability pension application: a sequence analysis study. Disabil Rehabil 2020;42:2161-9.

54 Ockander M, Timpka T. A female lay perspective on the establishment of long-term sickness absence. Int $J$ Soc Welf 2001;10:74-9.

55 Floderus B, Göransson S, Alexanderson K, Aronsson G, et al. Selfestimated life situation in patients on long-term sick leave. J Rehabil Med 2005;37:291-9.

56 Staland Nyman C, Andersson L, Spak F, et al. Exploring consequences of sickness absence - a longitudinal study on changes in self-rated physical health. Work 2009;34:315-24.
57 Statistical database of the social insurance institution of Finland. Available: https://www.kela.fi/web/en/statistical-database-kelasto [Accessed 1 Feb 2020].

58 Perhoniemi R, Blomgren J, Laaksonen M. Determinants of disability pension applications and awarded disability pensions in Finland, 2009 and 2014. Scand J Public Health 2020;48:172-80.

59 Karlsson H, Lehtinen V, Joukamaa M. Psychiatric morbidity among frequent attender patients in primary care. Gen Hosp Psychiatry 1995;17:19-25.

60 Bergh H, Marklund B. Characteristics of frequent attenders in different age and sex groups in primary health care. Scand J Prim Health Care 2003;21:171-7.

61 Salonen L, Blomgren J, Laaksonen M. From long-term sickness absence to disability retirement: diagnostic and occupational class differences within the working-age Finnish population. BMC Public Health 2020;20:e1078.

62 Karlsson NE, Carstensen JM, Gjesdal S, et al. Risk factors for disability pension in a population-based cohort of men and women on long-term sick leave in Sweden. Eur J Public Health 2008;18:224-31.

63 Gjesdal S, Bratberg E. Diagnosis and duration of sickness absence as predictors for disability pension: results from a three-year, multi-register based ${ }^{*}$ and prospective study. Scand J Public Health 2003;31:246-54. 